\title{
Commentary: What does a survey teach us?
}

\author{
Mariya Geube, MD, FASE
}

Chung and colleagues ${ }^{1}$ present a survey of cardiothoracic/ vascular surgeons and intensivists from major Canadian aortic centers regarding spinal cord ischemia prevention and treatment strategies during complex aortic surgery. The authors make a parallel between the findings of their survey and published society guidelines. ${ }^{2}$ There is an overall consensus among the surgeons regarding preoperative assessment of vertebral dominance, left subclavian artery revascularization, spinal drain placement and duration, and deliberate hypertension. Of note, the preferred method of distal aortic perfusion among the respondents is full cardiopulmonary bypass, which may not reflect the practice elsewhere.

The survey demonstrates areas of significant variability in the clinical practice even among the experts in the field. There is a consensus among surgeons $(100 \%)$ that spinal drains should be used in patients at high risk of spinal cord ischemia; however, only $67 \%$ of the intensivists believe this intervention is helpful. The survey is missing a large proportion of the intraoperative care team, because anesthesiologists were not surveyed. The authors make a point that in Canada, there is substantial overlap of intensivists and anesthesiologists, but it is unknown how many of the surveyed intensivists participate in the intraoperative management of these patients. In fact, spinal drain placement has class 1B recommendation for spinal cord protection, and the highest level of evidence among all other interventions. ${ }^{2,3}$

Surgeons are in agreement about a hemoglobin $(\mathrm{Hb})$ target $(>10 \mathrm{~g} / \mathrm{dL})$; in contrast, intensivists support conservative transfusion practice $(\mathrm{Hb}>8 \mathrm{~g} / \mathrm{dL})$. Although both values are somewhat arbitrary, the surgeons seem to be more concerned about the detrimental effect of acute

\footnotetext{
From the Department of Cardiothoracic Anesthesiology, Cleveland Clinic Foundation, Cleveland, Ohio.

Disclosures: Author has nothing to disclose with regard to commercial support.

Received for publication March 7, 2020; revisions received March 7, 2020; accepted for publication March 9, 2020; available ahead of print March 20, 2020.

Address for reprints: Mariya Geube, MD, FASE, Department of Cardiothoracic Anesthesiology, Cleveland Clinic Foundation, 9500 Euclid Ave, J4-328, Cleveland, OH 44195 (E-mail: geubem@ccf.org).

J Thorac Cardiovasc Surg 2022;163:24-5

$0022-5223 / \$ 36.00$

Copyright (c) 2020 by The American Association for Thoracic Surgery

https://doi.org/10.1016/j.jtcvs.2020.03.035
}

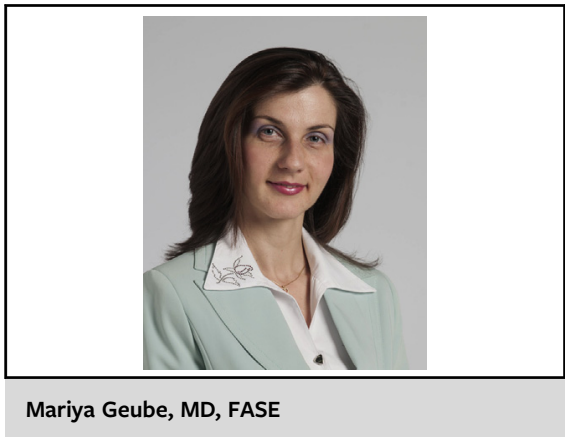

CENTRAL MESSAGE

Low level of evidence regarding prevention and management of spinal cord ischemia in complex aortic surgery stands behind significant variability in clinical

practice.

blood loss anemia on spinal cord perfusion than the intensivists. The authors refer to the TRICS trial, ${ }^{4}$ which concluded that transfusion for $\mathrm{Hb}$ less than 7.5 is noninferior than transfusion for $\mathrm{Hb}$ less than $9.5 \mathrm{~g} / \mathrm{dL}$ in adult patients undergoing cardiac surgery. The cited study included mainly patients undergoing coronary bypass or valve surgery and reported a composite outcome, but not spinal cord ischemia. Patients undergoing aortic surgery are a unique fraction of the critical care population, and the authors should use caution when calling for reevaluation of the target hemoglobin, based on studies performed in critically ill patients.

The major contribution of this survey is the "real-world" representation of the current practice as perceived by Canadian aortic experts. It generates more questions than provides answers. The limitation, as in other surveys, is that the responses can be influenced by own experience, recall for negative outcomes, and influence of recent cases.

One undoubted finding of this survey is that the lower the level of existing evidence is, regarding interventions for spinal cord protection, and the higher the degree of clinical practice variability. Best practices regarding optimal arterial pressure, spinal cord perfusion pressure, role of pharmacologic adjuncts and neuromonitoring, amount of spinal fluid drainage, and target cerebrospinal pressure require further investigations. 


\section{References}

1. Chung JC, Lodewyks CL, Forbes TL, Chu MWA, Peterson MD, Arora RC, et al. Prevention and management of spinal cord ischemia following aortic surgery: a survey of contemporary practice. J Thorac Cardiovasc Surg. 2022; 163:16-23.e7.

2. Etz C, Weigang E, Hartert M, Lonn L, Mestres CA, Di Bartolomeo R, et al. Contemporary spinal cord protection during thoracic and thoracoabdominal aortic surgery and endovascular aortic repair: a position paper of the vascular domain of the European Association for Cardiothoracic Surgery. Eur J Cardiothorac Surg. 2015;47:943-57.

3. Khan N, Smalley Z, Nesvick CL, Lee SL, Michael LM II. The use of lumbar drains in preventing spinal cord injury following thoracoabdominal aortic aneurysm repair: an updated systematic review and meta-analysis. J Neurosurg Spine. 2016;25:383-93.

4. Mazer D, Fergusson W, Fergusson DA, Belley-Cote E, Connolly K, Khanykin B, et al. Six-month outcomes after restrictive or liberal transfusion for cardiac surgery. N Engl J Med. 2018;379:1224-33.
See Article page 16.

\section{Commentary: Spinal cord ischemia following aortic surgery: Survey says?}

\author{
Lars Stangenberg, $\mathrm{MD}, \mathrm{PhD},{ }^{\mathrm{a}}$ and \\ Neel R. Sodha, MD
}

On Family Feud, a popular North American television gameshow, contestants are asked to guess the most common responses to a variety of survey questions. With the famous catch phrase "Survey says...?," the host reveals the most common responses, rewarding contestants for matching answers. Chung and colleagues ${ }^{1}$ surveyed surgeons and intensivists across Canada to characterize current practices for the prevention and management of spinal cord ischemia (SCI) in the setting of aortic surgery. Unlike the gameshow, Chung and colleagues ${ }^{1}$ found significant variability and lack of consensus in key management areas among the physicians surveyed.

The authors highlight that SCI can be a devastating complication after aortic surgery, yet guidelines for prevention and management are based on limited data, often levels $\mathrm{B}$ and $\mathrm{C}$ supportive evidence. Currently available guidelines are broad and lack the granularity needed for detailed protocols. $^{2-4}$ This has led to individualized institutional algorithms and a void of best practice recommendations. Recognizing this, the authors collaborated with national experts in the field to develop detailed surveys addressing key areas to

\footnotetext{
From the a Division of Vascular and Endovascular Surgery, Beth Israel Deaconess Medical Center, Harvard Medical School, Boston, Mass; and ${ }^{\mathrm{b}}$ Division of Cardiac Surgery, Rhode Island Hospital, Alpert Medical School, Brown University, Providence, RI.

Disclosures: Authors have nothing to disclose with regard to commercial support.

Received for publication March 8, 2020; revisions received March 8, 2020; accepted for publication March 9, 2020; available ahead of print March 31, 2020.

Address for reprints: Neel R. Sodha, MD, Division of Cardiac Surgery, Alpert Medical School, Brown University, 2 Dudley St, MOC Suite 360, Providence, RI 02905 (E-mail: nsodha@lifespan.org).

J Thorac Cardiovasc Surg 2022;163:25-6

0022-5223/\$36.00

Copyright (c) 2020 by The American Association for Thoracic Surgery

https://doi.org/10.1016/j.jtcvs.2020.03.058
}

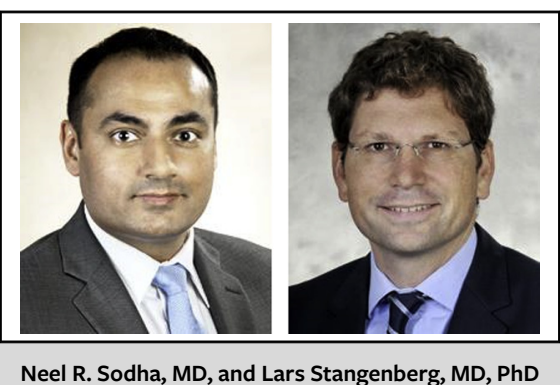

CENTRAL MESSAGE

Prevention and management
strategies addressing spinal cord
ischemia after aortic surgery are
variable. Highly defined guide-
lines are lacking and based on
limited evidence. A survey of
clinical practice highlights areas
of controversy and points to the
need for improved research.

prevent and manage SCI. The comprehensive questionnaires nicely addressed key decision points that arise in the daily management of this patient population, and importantly provide data on real-world clinical practice across a multitude of centers and specialties with survey response rates of more than $90 \%$. The study was not meant to analyze outcomes or provide evidence for best practices; rather, the major influence of this study is in demonstrating the wide variability in managing SCI in these patients. The authors demonstrate a lack of consensus in multiple areas, including transfusion thresholds, staged operations, perioperative management of antihypertension medications, temperature management, and even the effectiveness of lumbar drains-only two-thirds of intensive care unit consultants 